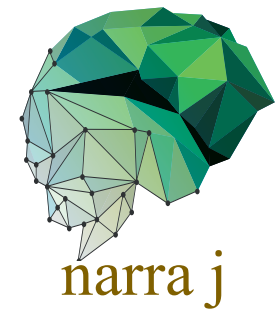

Original Article

\title{
Molecular docking of two cytotoxic compounds from Calotropis gigantea leaves against therapeutic molecular target of pancreatic cancer
}

\author{
Agnia Purnama1, Vivi Mardina², Kana Puspita3*, Intan Qanita4, Diva R. Rizki4, \\ Kartini Hasballah 5 , Mudassar Iqbal ${ }^{6}$ and Murniana Sarong ${ }^{1}$ \\ ${ }^{1}$ Department of Chemistry, Universitas Syiah Kuala, Banda Aceh, Aceh, Indonesia; ${ }^{2}$ Department of Biology, Faculty of \\ Engineering, Universitas Samudra, Langsa, Aceh, Indonesia; 3Department of Chemistry Education, Faculty of Education \\ and Teacher Training, Universitas Syiah Kuala, Banda Aceh, Aceh, Indonesia; 4 School of Medicine, Universitas Syiah \\ Kuala, Banda Aceh, Aceh, Indonesia; 5 Department of Pharmacology, School of Medicine, Universitas Syiah Kuala, Banda \\ Aceh, Aceh, Indonesia; ${ }^{6}$ Department of Agricultural Chemistry and Biochemistry, Agricultural University, Peshawar, \\ Pakistan
}

*Corresponding author: kana.puspita.usk@gmail.com

\begin{abstract}
The utilization of natural compounds as therapeutic agents to treat pancreatic cancer has recently focused on natural drug research. Calotropis gigantea has long been believed to be a medicinal plant that helps in treating various diseases. The bioactive compounds 9metoxipinoresinol and isoliquiritigenin isolated from C. gigantea leaves are proven to act as therapeutic agents by inhibiting the cancer cell growth of Panc-1 cells. This study aimed to screen the potential molecular inhibition mechanisms of 9-metoxipinoresinol and isoliquiritigenin against pancreatic cancer development in-silico. We analyzed the activity of the aforementioned two compounds as inhibitors of several proteins that play a role in the growth of pancreatic cancer cells, such as GCNT3, GOT1, c-Met, PPARy, BUB1, and $\mathrm{NF}-\kappa \beta$, through molecular docking investigation. Our data suggested that 9metoxipinoresinol and isoliquiritigenin were able to have well interaction with the target proteins, in which the predicted affinity energy ranged between -6.8 and $8.7 \mathrm{kcal} / \mathrm{mol}$. The docking scores of 9-metoxipinoresinol and isoliquiritigenin were higher than the standard drug used (gemcitabine). Based on the binding affinity energy, GCNT3 and BUB1 are potentially to be used as target molecules for cancer therapy using 9-metoxipinoresinol and isoliquiritigenin, respectively.
\end{abstract}

Keywords: Panc-1 cells, Calotropis gigantea, GCNT3, BUB1, natural compound

\section{Introduction}

Calotropis gigantea is one of the herbs used for treatment of a variety of diseases. The bioactivity of various plant extracts has been presented to possess anticancer, antimalarial, antirheumatic, and antidiabetic potential associated with various secondary metabolites [1]. Natural compounds of 9-metoxipinoresinol and isoliquiritigenin, isolated from extract of $C$. gigantea, showed a potent cytotoxic activity against pancreatic cells[2]. Both compounds have an inhibition values $\left(\mathrm{IC}_{50}\right)$ below $5 \mu \mathrm{M}$ against Panc-1 cells, which are lower than that of standard drug - gemcitabine $\left(\mathrm{IC}_{50}>25 \mu \mathrm{M}\right)[2]$. 
Pancreatic cancer is one of the deadliest diseases and the percentage of deaths reaches $90 \%$ of the total cases [3]. The innovative treatment for this disease is continually being developed, where natural compounds have been considered as an alternative source to inhibit cancer cell growth by targeting its growth receptors. In this light, the Kirsten rat sarcoma viral oncogene homolog (KRAS) mutation pathway mostly influences the cell growth of pancreatic cancer. Glucosaminyl (N-acetyl) transferase 3, mucin type (GCNT3) and nuclear factor kappa beta (NF$\kappa \beta)$ are proteins that play important roles in the KRAS pathway $[4,5]$. Other receptors such as glutamate oxaloacetate transaminase 1 (GOT1), tyrosine-protein kinase Met(c-Met), peroxisome proliferator-activated receptor (PPAR) $\gamma$, and budding uninhibited by benzimidazoles 1 (BUB1) are also cancer receptors used as therapeutic targets by suppressing the cell proliferation process [6-8]. Based on our previous research, the active compound in the C. gigantea, caloptropone, has a potent affinity energy in binding to the pancreatic cancer receptor, with the most active value of $-9.1 \mathrm{kcal} / \mathrm{mol}$ (unpublished). The search for new target molecules of 9-metoxipinoresinol and isoliquiritigenin could be more efficiently conducted with the information from molecular docking simulation.

Molecular docking is a method of analyzing new drugs against their target proteins. The active compound works by binding to the target protein through different orientations. This docking method can provide the optimal orientation information by predicting the affinity energy and compound activity [9]. This method relies on the $3 \mathrm{D}$ structure information of a target and the electronics of the ligand to the target[10]. This article presents information about the affinity energy produced by 9-metoxipinoresinol and isoliquiritigenin through the molecular docking method. In comparison to the traditional in-vitro or in-vivo study, computational study using molecular docking could provide fast screening of probable molecular interaction. However, the results of computational studies should be confirmed using laboratory-based studies.

\section{Methods}

\section{Hardware and software}

Docking simulations were carried out on an Intel Celeron N3350 Acer computer, 1.00 GB memory processor (RAM), 32-bit operating system, Windows 10 pro. LigPlot +1.5.4, PyMOL 2.4 (Delano Scientific LLC, Italy), ChemDraw Ultra 12.0, Chem3D Pro 12.0, Gauss view, Discovery Studio Visualizer 4 and AutoDock Vina assisted by AutoDock Tools 5.6 were used during the simulations.

\section{Ligand structure preparation}

The structures of isoliquiritigenin (CID: 638278) and gemcitabine (CID: 60750) were obtained from the PubChem chemical structure database (www.pubchem.ncbi.nlm.nih.gov). The ligand structure was converted from the SDF format into PDB format using Pymol 2.4 software. The 9metoxipinoresinol structure was created using ChemDraw Ultra 12.0, then converted to $3 \mathrm{D}$ with chem3D pro12.o. The structure of 9-metoxipinoresinol was optimized using Gaussian display and saved in PDB file format.

\section{Proteins' preparation}

Protein structures of GCNT3 (PDB ID: 2GAM), GOT1 (PDB ID: 3IIo), c-Met (PDB ID: 6SD9), PPAR $\gamma$ (PDB ID: 3U9Q), BUB1 (PDB ID: 4QPM), NF- $\kappa \beta$ (PDB ID: 1SVC), SOX2 (PDB ID: IGTo), and ADAM10 (GDP ID: 6BE6 were retrieved from the Protein Data Bank (PDB) (https://www.rscb/pdb.org). All protein data were stored in pdb format. Protein structures were prepared by removing molecules and ligands using Discovery Studio Visualizer 4.

\section{Molecular docking}

The 3D structure of the ligand and protein was added with polar hydrogen atoms and Gasteiger partial charge were carried out in the AutoDock Tools 1.5.6.rc3 and saved in pdbqt for further analysis. AutoDock Vina was used in the docking simulation with a predetermined grid box position and protein macromolecules remained rigid during the docking simulation[11]. Ten docking pose protein-ligand conformations were selected from Vina's AutoDock scoring function, and they were ranked according to their affinity energy. The conformation with the best 
affinity energy was visualized using LigPLot +1.5 .4 to show hydrogen bond interactions, hydrophobic interactions and bond distances, while the $3 \mathrm{D}$ interactions were visualized using PyMOL 3.1.

\section{Results}

\section{Docking score}

Affinity energy through ligand and protein binding is presented in Table 1. The 9metoxipinoresinol and isoliquiritigenin bind to this target with high binding energies. Affinity energy produced was relatively high with best affinity energy for 9-metoxipinoresino against GCNT3 $(-8.7 \mathrm{kcal} / \mathrm{mol})$, whereas isoliquiritigenin had the best docking conformation with an affinity energy of $-8.7 \mathrm{kcal} / \mathrm{mol}$ against BUB1. The affinity energies of 9-metoxipinoresinol and isoliquiritigenin also had better values than the reference drug (gemcitabine). Gemcitabine only produced the best affinity energy of $7.1 \mathrm{kcal} / \mathrm{mol}$ against GOT1.

\section{Interaction of ligand and protein}

The interaction formed between the ligand and protein affects the affinity energy. Figure 1-3 show the polar hydrogen and hydrophobic interactions between the compound ligands and the target proteins. Gemcitabine has the best affinity energy in GOT1. This energy is generated from

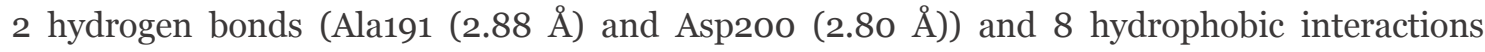
(Asp237, Thr202, Arg236, He358, Pro201, Cys192, Ser231, Ala230) (Figure 1). The strongest hydrogen bond interaction occurred at Asp200 via hydrogen bonding to the gemcitabine atom with the oxygen atom (C terminal) of the Asp200.

The best affinity energy produced by isoliquiritigenin was in BUB1. Their interaction consists of

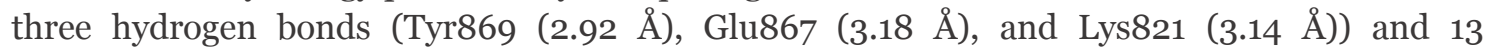
hydrophobic interactions (Asp921, Asn922, Gly796, Glu795, Val801, Gly794, He945, Val819, Asp946, He924, Ala799, Met850, Leu868) (Figure 2). The strongest hydrogen bond occurred with the oxygen atom of the C-terminal at His144 with the hydrogen atom on isoliquiritigenin.

The 9-metoxipinoresinol had the most effective energy against GCNT3 and the interactions

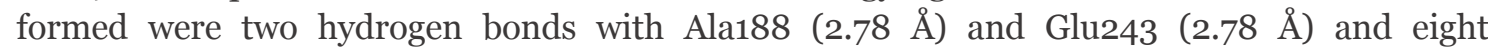
hydrophobic interactions with Tyr187, Glu320, Arg109, Ala287, Lys288, Val254, Trp356 and Ser286 (Figure 3). The strongest polar hydrogen interaction occurred at hydrogen atom of 9methoxypinoresinol with the oxygen atom of the side chain in Glu243.

\section{Discussion}

Our data suggest that two natural compounds derived from C. gigantea, 9-metoxipinoresinol and isoliquiritigenin, have a higher affinity energy than gemcitabine for each pancreatic cancer receptor, which may be better at inhibiting the growth of pancreatic cancer cell processes (Table 1). The value binding affinity informs the likelihood of interaction between the tested molecules, thus, might suggest the potential inhibition. Affinity energy greater than $5 \mathrm{kcal} / \mathrm{mol}$ indicates an effect on the receptor [12] and the resulting affinity energy guides us to the strength of the binding bond between the ligand and the receptor.

The 9-metoxipinoresinol has the best binding to the GCNT3. GCNT3 upregulates mucin biosynthesis and is associated to KRAS mutation [5,13]. The 9-metoxipinoresinol could be used as a new inhibitor to treat pancreatic cancer via the GCNT3 pathway, evidenced by the affinity energy that is similarly produced by talniflumate against the same protein[5]. The 9metoxipinoresinol is a new compound and studies confirming its activity as an inhibitor against other cancer cells are still very rare. However, the parent compound of 9-metoxipinoresinol, pinoresinol, has been shown to inhibit the growth of several cancer cells. Pinoresinol attenuated LPS-induced phosphorylation of ERK1/2 MAPK and inhibit mutant p53 protein, which are targets for pancreatic cancer therapy [14-16]. Inhibition of c-Met decreased ERK 1/2 [17]. Meanwhile, inhibition of PPARG and BUB1 may have an impact on p53 activity, where PPARG 
plays a role in activating the p53 gene and BUB1 involved in the p53 signaling pathway $[18,19]$. Pinoresinol is also reported to inhibit NF- $\kappa \beta$ and, therefore is important in reducing cancer cell activity[20].

Table 1. Affinity energy and molecular interaction of gemcitabine, isoliquiritigenin, and 9-metoxipinoresinol with proteins associated with pancreatic cancer cells

\begin{tabular}{|c|c|c|c|c|}
\hline Protein & Ligand & $\begin{array}{l}\text { Affinity energy } \\
\text { (kcal/mol) }\end{array}$ & Interaction & Amino acids \\
\hline \multirow[t]{6}{*}{ GCNT3 } & \multirow[t]{2}{*}{ Gamcitabine } & \multirow[t]{2}{*}{-6.5} & HI & $\begin{array}{l}\text { Ser317, Ala188, Tyr187, Lys401, Cys217, Tyr288, } \\
\text { Glu320 }\end{array}$ \\
\hline & & & PHI & Arg378, Asp319, Asn40o \\
\hline & \multirow[t]{2}{*}{ Isoliquiritigenin } & \multirow[t]{2}{*}{-7.8} & $\mathrm{HI}$ & $\begin{array}{l}\text { Glu243, Val354, Asn400, Tyr228, Val38o, Ser286, } \\
\text { Trp356, Glu320, Gly285 }\end{array}$ \\
\hline & & & PHI & Asp346, Arg378, Lys401 \\
\hline & \multirow[t]{2}{*}{ 9-metoxipinoresinol } & \multirow[t]{2}{*}{-8.7} & HI & $\begin{array}{l}\text { Tyr187, Glu320, Arg109, Ala287, Lys288, Val254, } \\
\text { Trp356, Ser286 }\end{array}$ \\
\hline & & & PHI & Ala188, Glu243 \\
\hline \multirow[t]{5}{*}{ GOT1 } & \multirow[t]{2}{*}{ Gamcitabine } & \multirow[t]{2}{*}{-7.1} & HI & $\begin{array}{l}\text { Asp237, Thr202, Arg236, He358, Pro201, Cys192, } \\
\text { Ser231, Ala230 }\end{array}$ \\
\hline & & & PHI & Ala191, Asp200 \\
\hline & \multirow[t]{2}{*}{ Isoliquiritigenin } & \multirow[t]{2}{*}{-7.9} & $\mathrm{HI}$ & $\begin{array}{l}\text { Gly108, Ser258, Phe19, tYr264, Lys259, Trp141, } \\
\text { Tyr226, Asn195, Ala225, Thr110 }\end{array}$ \\
\hline & & & PHI & Arg267, Arg267, Arg267, Asp223 \\
\hline & 9-metoxipinoresinol & -7.7 & $\begin{array}{l}\text { HI } \\
\text { PHI }\end{array}$ & $\begin{array}{l}\text { Phe19, Tyr264, Thr110, Ser258, Trp141, Tyr226 } \\
\text { Arg267, Arg267, Lys259 }\end{array}$ \\
\hline \multirow[t]{6}{*}{ c-Met } & \multirow[t]{2}{*}{ Gamcitabine } & \multirow[t]{2}{*}{-6.3} & HI & $\begin{array}{l}\text { Ala1221, Phe1134, Met1131, Val1220, Leu1195, } \\
\text { His1202, Phe1200, Gly1224 }\end{array}$ \\
\hline & & & PHI & Glu1127, Asp1222 \\
\hline & \multirow[t]{2}{*}{ Isoliquiritigenin } & \multirow[t]{2}{*}{-8.1} & $\mathrm{HI}$ & $\begin{array}{l}\text { Val1092, Phe1223, Lau1157, Ala1108, Gly1163, } \\
\text { Met1211, He1084 }\end{array}$ \\
\hline & & & PHI & Asp1222, Lys1110 \\
\hline & \multirow[t]{2}{*}{ 9-metoxipinoresinol } & \multirow[t]{2}{*}{-8.0} & HI & $\begin{array}{l}\text { Ala1108, Val1092, Phe1223, Glu1127, Ala1221, } \\
\text { Phe1134, Met1131, Asp1222, Leu1140, Pro1158, } \\
\text { Lys1110, Met116o, Leu1157 }\end{array}$ \\
\hline & & & PHI & \\
\hline \multirow[t]{5}{*}{ PPARG } & Gamcitabine & -6.4 & $\begin{array}{l}\text { HI } \\
\text { PHI }\end{array}$ & $\begin{array}{l}\text { Lys457, Leu465, He456, Tyr473, Lys474 } \\
\text { Leu453, Asp475, Gln470 }\end{array}$ \\
\hline & \multirow[t]{2}{*}{ Isoliquiritigenin } & \multirow[t]{2}{*}{-7.6} & HI & $\begin{array}{l}\text { Leu353, Phe363, Cys285, Ser289, His323, Leu453 } \\
\text { Tyr473, Leu469, His449, Phe282, Phe36o, He281, } \\
\text { Leu356 }\end{array}$ \\
\hline & & & PHI & Ala278 \\
\hline & \multirow[t]{2}{*}{ 9-metoxipinoresinol } & \multirow[t]{2}{*}{-8.6} & HI & $\begin{array}{l}\text { He341, Arg288, He326, Leu3440, Leu333, } \\
\text { Met364, ser289, Phe282, Cys285, Leu330, Tyr327 }\end{array}$ \\
\hline & & & PHI & His449, Ser342, Glu343, Ser342 \\
\hline \multirow{4}{*}{ BUB1 } & Isoliquiritigenin & -8.7 & HI & $\begin{array}{l}\text { Asp921, Asn922, Gly796, Glu795, Val801, Gly794, } \\
\text { He945, Val819, Asp946, He924, Ala799, Met850, } \\
\text { Leu868 }\end{array}$ \\
\hline & & & PHI & Tyr869, Glu867, Lys821 \\
\hline & 9-metoxipinoresinol & -8.0 & HI & $\begin{array}{l}\text { Met85o, Val801, Gly794, Thr873, Glu795, Leu875, } \\
\text { Asp921, Asn876, He924, Leu793, Val819, He945, } \\
\text { Leu868, Tyr869 }\end{array}$ \\
\hline & & & PHI & None \\
\hline NF- $\kappa \beta$ & Gamcitabine & $-5 \cdot 3$ & HI & Lys149, Leu143 \\
\hline & & & PHI & Glu152, Thr153, Arg157, Ser113 \\
\hline & Isoliquiritigenin & -6.8 & $\begin{array}{l}\text { HI } \\
\text { PHI }\end{array}$ & $\begin{array}{l}\text { Val61, Tyr6o, Val145, Lys149, Thr153, Ser113 } \\
\text { Ala62, His144, Thr146, Arg157 }\end{array}$ \\
\hline & 9-metoxipinoresinol & -7.1 & HI & $\begin{array}{l}\text { Asp121, Leu143, Val145, Val61, Thr146, His144, } \\
\text { Thr153 }\end{array}$ \\
\hline & & & PHI & Ser113, Arg157, Arg157, Lys149 \\
\hline
\end{tabular}

HI: hydrophobic interaction, PHI: polar H interaction 

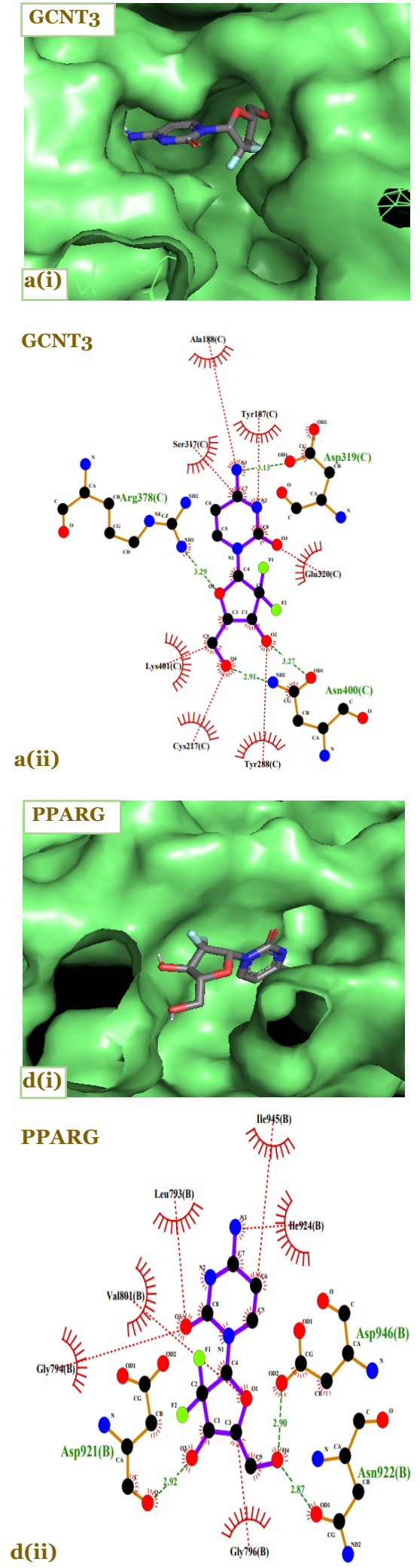
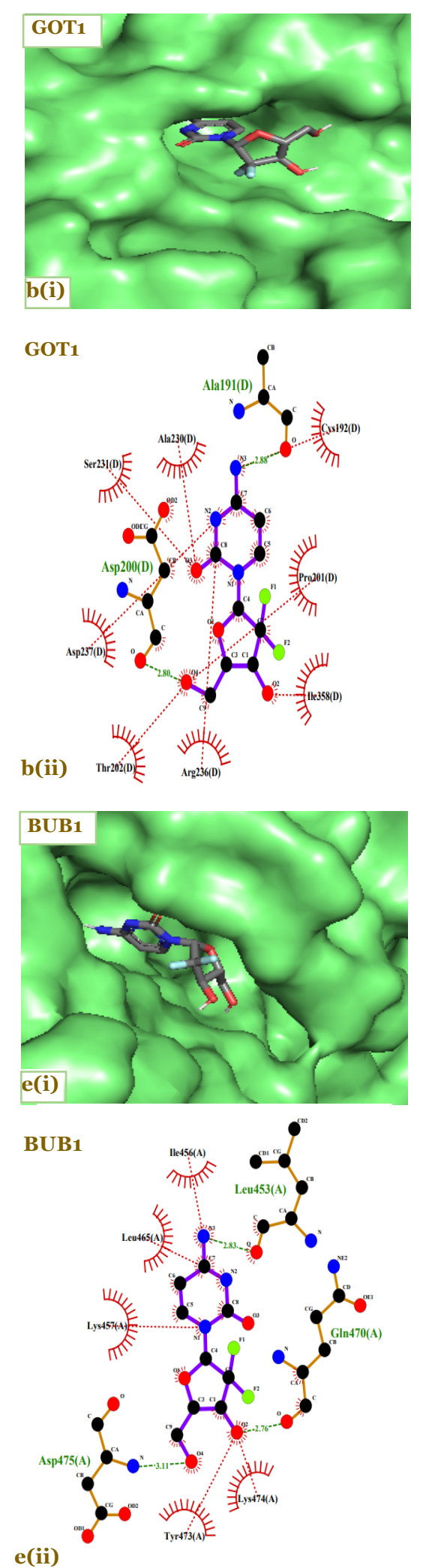
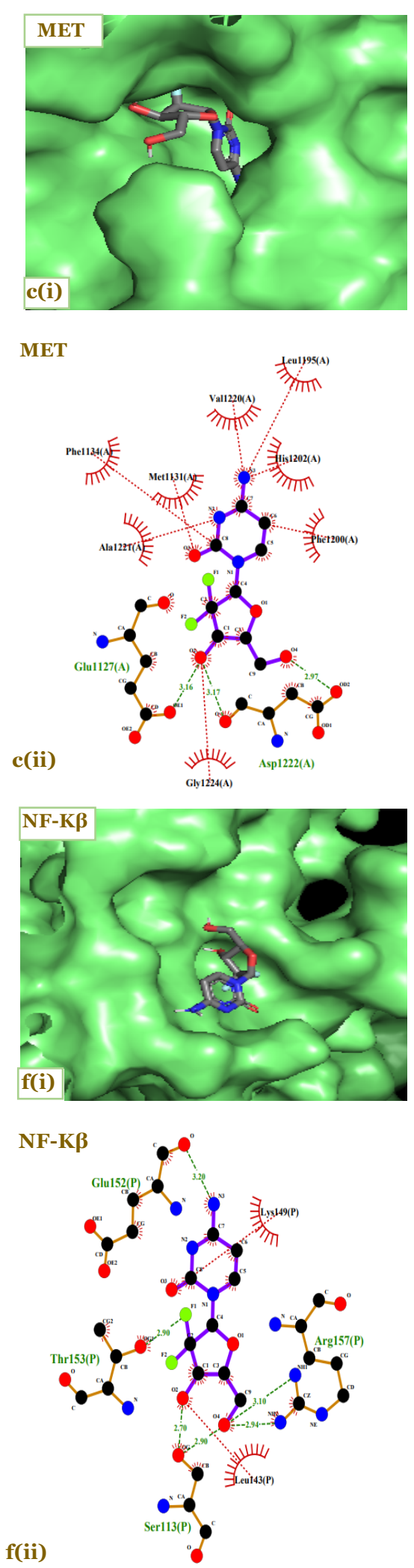

Figure 1. Interaction of gemcitabine with pancreas cancer proteins(a) GCNT3, (b) GOT1, (c) MET, (d) PPARG, (e) BUB1 and (f) NF- $\kappa \beta$. Panel is Showing 3D view of the interaction of gemcitabine with pancreas cancer proteins. Panel ii showing 2D view and overlay of gemcitabine in amino acids of the pancreas cancer proteins. GCNT3: glucosaminyl (N-Acetyl) transferase 3, GOT1: mucin type glutamate oxaloacetate transaminase 1, MET: metformin, PPARG: peroxisome proliferator-activated receptor, BUB1: budding uninhibited by benzimidazole 1 and NF-к $\beta$ : nuclear factor kappa beta. 

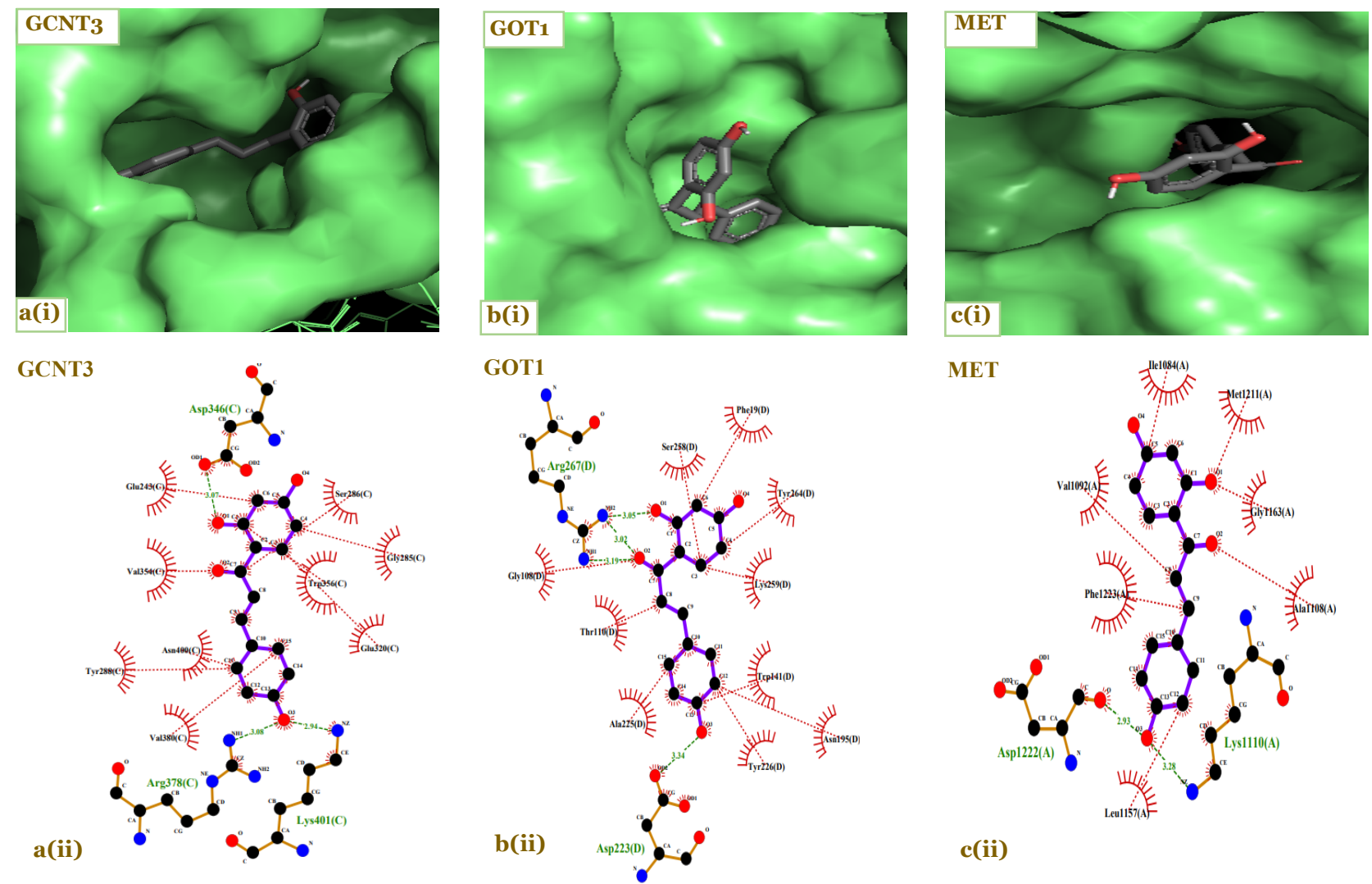

c(ii)
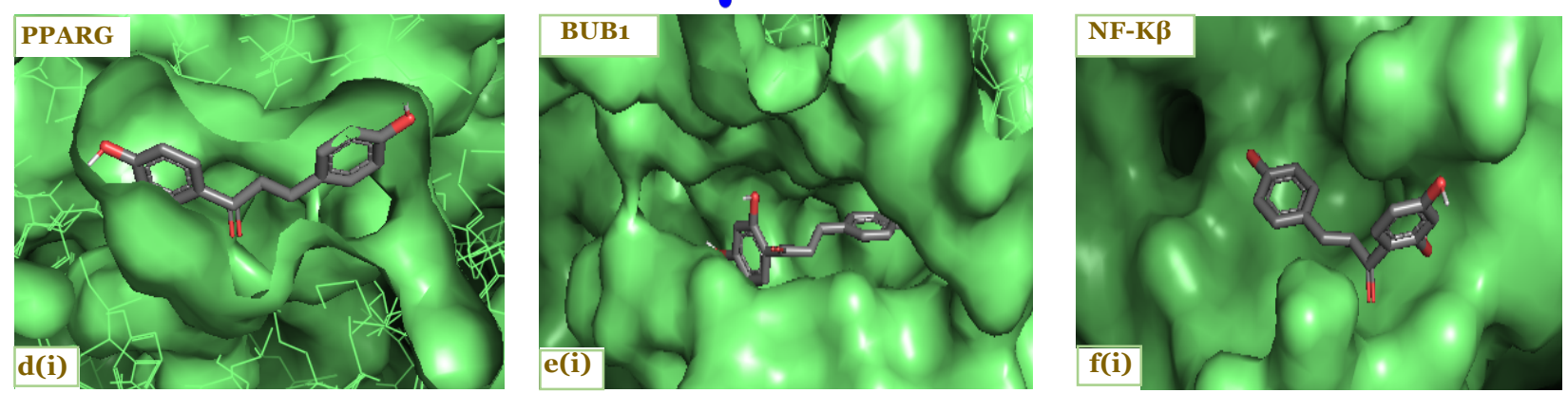

PPARG

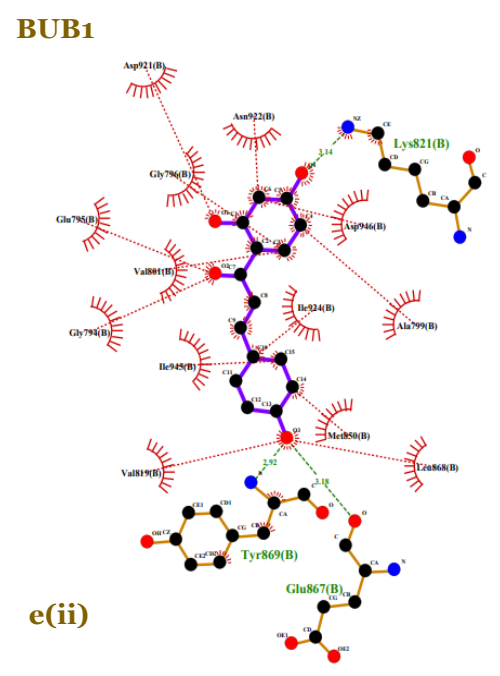

NF-K $\beta$
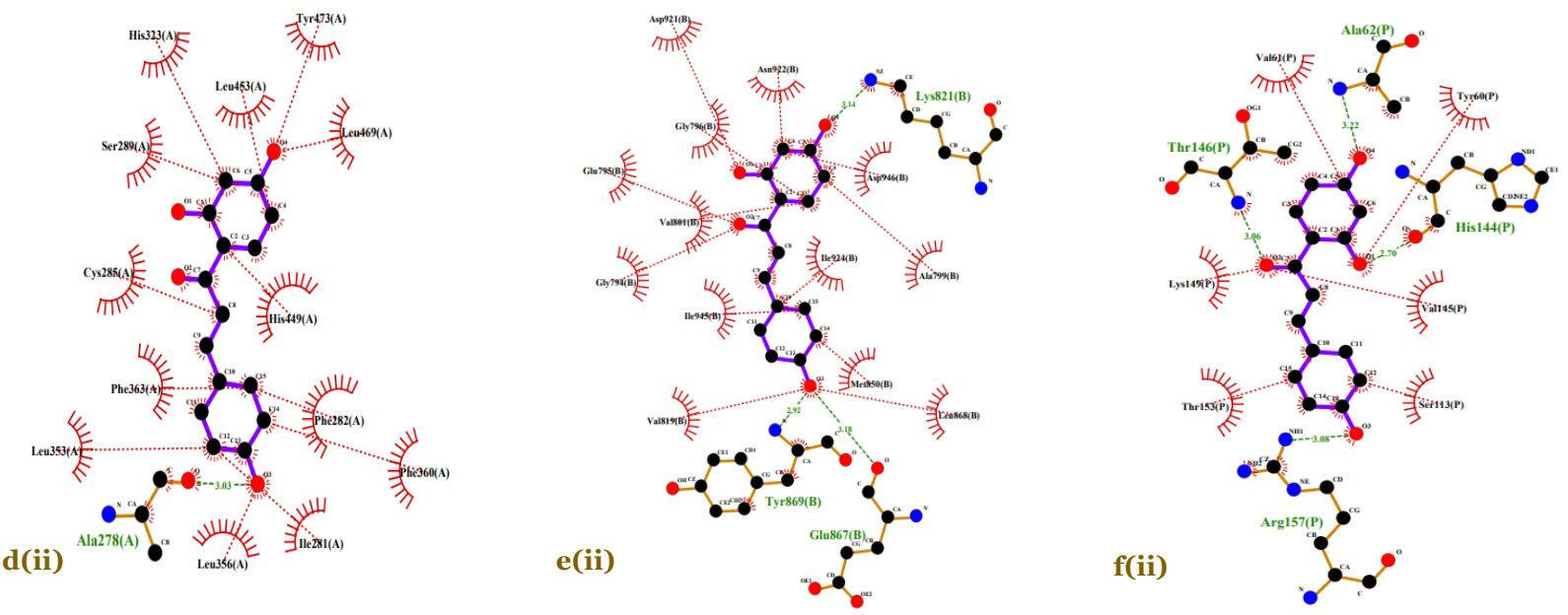

Figure 2. Interaction of isoliquiritigenin with pancreas cancer proteins (a) GCNT3, (b) GOT1, (c) MET, (d) PPARG, (e) BUB1 and (f) NF- $\kappa \beta$. Panel i showing 3D view of the interaction of gemcitabine with pancreas cancer proteins. Panel ii showing 2D view and overlay of gemcitabine in amino acids of the pancreas cancer proteins. GCNT3: glucosaminyl (N-Acetyl) transferase 3, GOT1: mucin type glutamate oxaloacetate transaminase 1, MET: metformin, PPARG: peroxisome proliferator-activated receptor, BUB1: budding uninhibited by benzimidazole 1

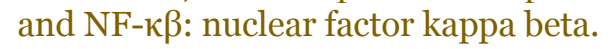




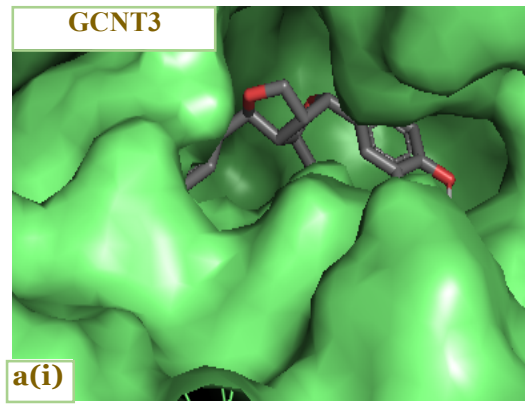

GCNT3

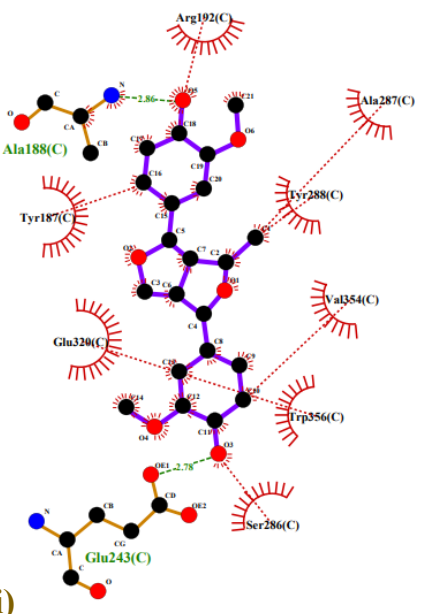

a(ii)

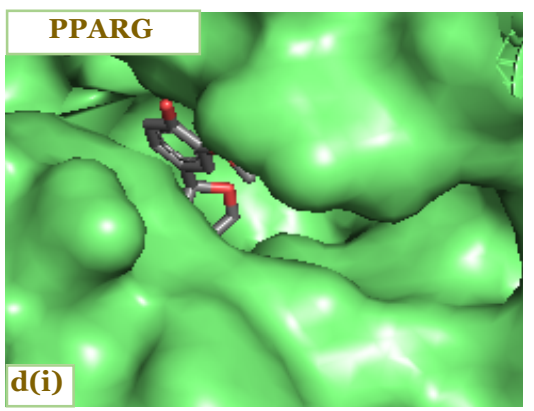

PPARG

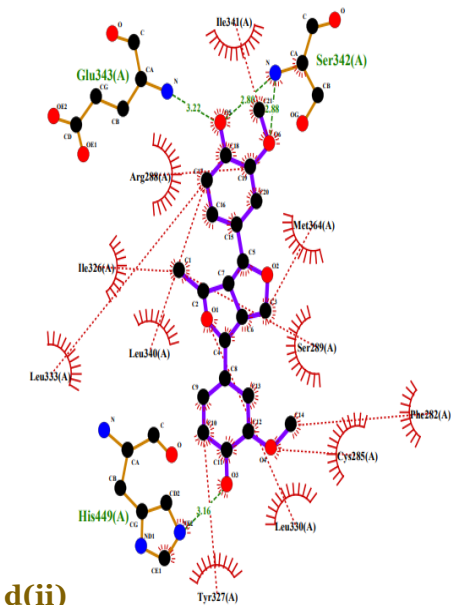

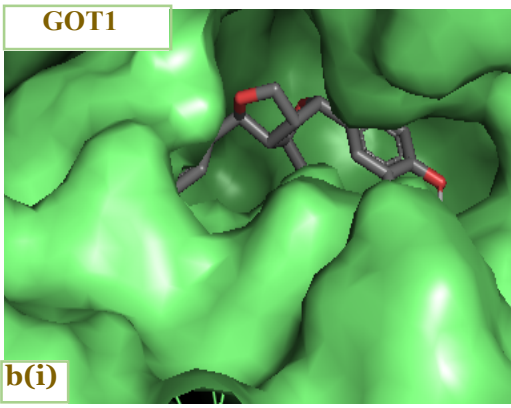

GOT1

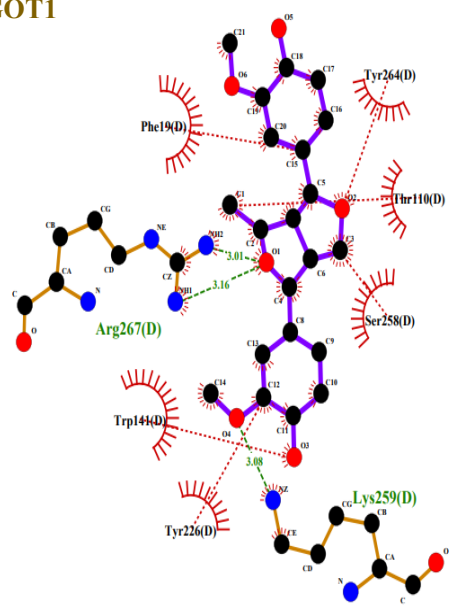

b(ii)

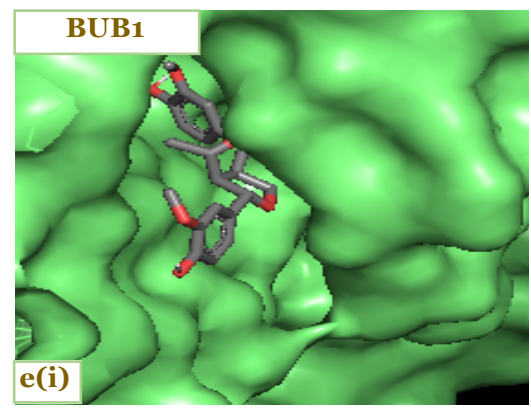

BUB1

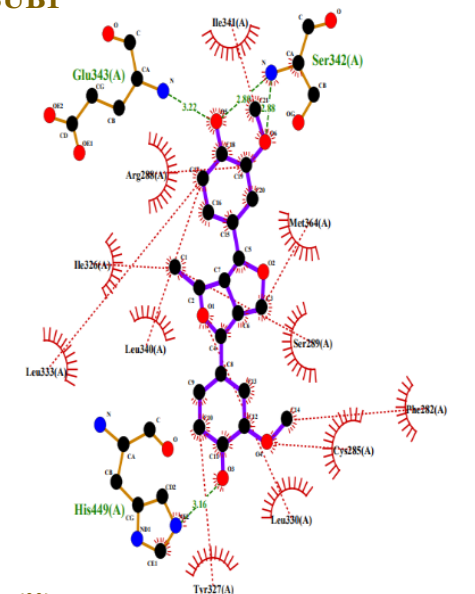

e(ii)
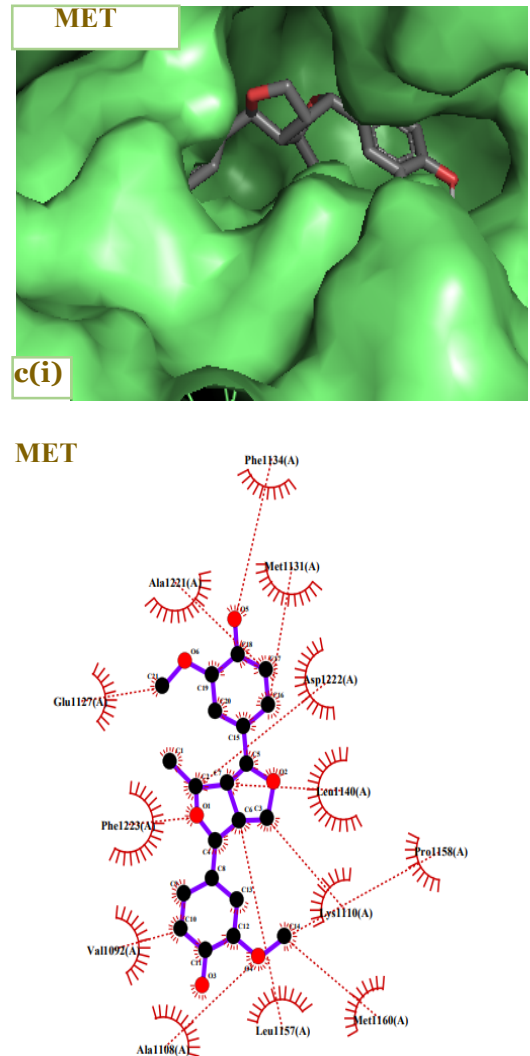

c(ii)

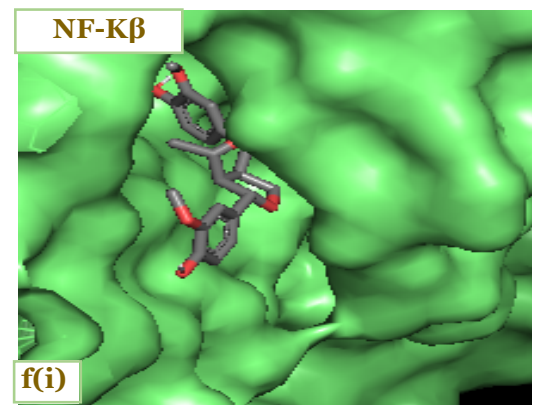

NF-K $\beta$

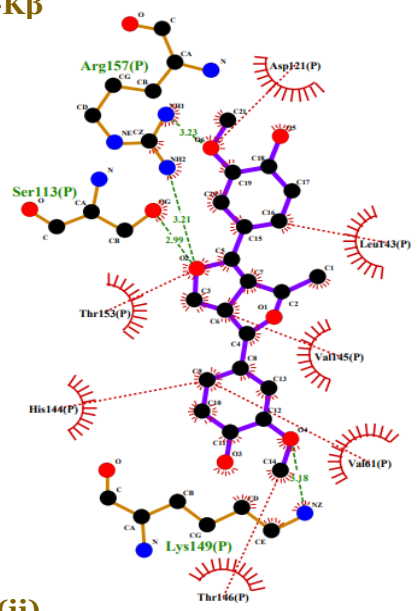

f(ii)

Figure 3. Interaction of 9-metoxipinoresinol with pancreas cancer proteins (a) GCNT3, (b) GOT1, (c) MET, (d) PPARG, (e) BUB1 and (f) NF- $\kappa \beta$. Panel i showing 3 D view of the interaction of gemcitabine with pancreas cancer proteins. Panel ii showing 2D view and overlay of gemcitabine in amino acids of the pancreas cancer proteins. GCNT3: glucosaminyl (N-Acetyl) transferase 3, GOT1: mucin type glutamate oxaloacetate transaminase 1, MET: metformin, PPARG: peroxisome proliferator-activated receptor, BUB1: budding uninhibited by benzimidazole 1 and NF-к $\beta$ : nuclear factor kappa beta. 
The isoliquiritigenin has the greatest affinity energy for the BUB1. BUB1 triggers the growth of pancreatic cancer cells and overexpression of BUB1 induces tumorigenesis and cell proliferation [21]. Significant expression of the mitotic kinase BUB1 also associates with various types of cancer and correlates with a poor clinical prognosis [22]. Isoliquiritigenin has been shown to reduce PI3K/AKT signaling pathways which is a developmental pathway for pancreatic cancer cells [14,23]. Inhibition of BUB1 and PPARG by isoliquiritigenin could consequently cause the reduction of PI3K/AKT signaling pathways owing to the abilities of BUB1 and PPARG to activate the $\mathrm{PI}_{3} \mathrm{~K} / \mathrm{AKT}$ via TGF- $\beta$ upregulation $[24,25]$. In addition, c-Met is also critical in activation of PIK3/AKT [26] and isoliquiritigenin is able to directly inhibit the activity of NF-к $\beta$ [27].

The affinity energy of 9-metoxipinoresinol for GCNT3 occurs through hydrophobic and polar hydrogen interactions and the best interaction was shown in the amino acid of Glu243. This interaction can be used as a target inhibitor for GCNT3. A previous analysis found that the inhibitor for the DYRK1B receptor bound to Glu243 and exhibited great activity against protein inhibitor [28].

\section{Conclusions}

Our molecular docking data suggest that 9-metoxipinoresinol and isoliquiritigenin bind well to pancreatic cancer receptors, GCNT3, GOT1, c-Met, PPAR $\gamma$, BUB1, and NF- $\kappa \beta$, with higher docking scores, compare to gemcitabine. The 9-metoxipinoresinol produces the best docking score on GCNT3 while soliquiritigenin on BUB1 with affinity energy of $8.7 \mathrm{kcal} / \mathrm{mol}$. We suggest further investigation for in-vitro experiments to prove the mechanism of 9-metoxipinoresinol and isoliquiritigenin activities against pancreatic cancer receptors.

\section{Declarations}

\section{Ethics approval}

Not Applicable

\section{Acknowledgments}

Authors appreciate the collaboration of Universitas Syiah Kuala, Indonesia and Agricultural University, Pakistan during the study and preparation of this article.

\section{Conflict of interest}

The authors declare that they have no competing interests.

\section{Funding}

None.

\section{How to cite}

PurnamaA, Mardina V, Puspita K, et al. Molecular docking of two cytotoxic compounds from Calotropis gigantea leaves against therapeutic molecular target of pancreatic cancer. Narra $\mathrm{J}$ 2021; 1(2): e37. http://doi.org/10.52225/narraj.v1i2.37.

\section{References}

1. Damodaran B, Prabhu B, Vinothkumar G, et al. RNA sequencing-based transcriptomic profiles of HeLa, MCF-7 and A549 cancer cell lines treated with Calotropis gigantea leaf extracts. Gene Reports 2021;23:101119.

2. Nguyen $\mathrm{KDH}$, Dang PH, Nguyen HX, et al. Phytochemical and cytotoxic studies on the leaves of Calotropis gigantea. Bioorganic Med Chem Lett 2017;27:2902-2906. 
3. Sung H, Ferlay J, Siegel RL, et al. Global cancer statistics 2020: GLOBOCAN estimates of incidence and mortality worldwide for 36 cancers in 185 countries. CA Cancer J Clin 2021: 71(3):209-249.

4. Pramanik KC, Makena MR, Bhowmick K, Pandey MK. Advancement of NF-kB signaling pathway: A novel target in pancreatic cancer. Int J Mol Sci 2018;19(12):3890.

5. Rao C V, Janakiram NB, Madka V, et al. Small-molecule inhibition of GCNT3 disrupts mucin biosynthesis and malignant cellular behaviors in pancreatic cancer. Cancer Res 2016;76:1965-1974.

6. Aier I, Semwal R, Sharma A, Varadwaj PK. In silico identification of therapeutic compounds against microRNA targets in drug-resistant pancreatic ductal adenocarcinoma. J Biomol Struct Dyn 2020:1-9.

7. Holt MC, Assar Z, Beheshti Zavareh R, et al. Biochemical Characterization and Structure-Based Mutational Analysis Provide Insight into the Binding and Mechanism of Action of Novel Aspartate Aminotransferase Inhibitors. Biochemistry 2018;57:6604-6614.

8. Liu H, Zhou Q, Wei W, et al. The potential drug for treatment in pancreatic adenocarcinoma: A bioinformatical study based on distinct drug databases. Chin Med 2020;15:26.

9. Ramírez D, Caballero J. Is it reliable to take the molecular docking top scoring position as the best solution without considering available structural data? Molecules 2018; 23(5):1038.

10. Pinzi L, Rastelli G. Molecular docking: Shifting paradigms in drug discovery. Int J Mol Sci 2019; 20(18):4331.

11. Azam SS, Abbasi SW. Molecular docking studies for the identification of novel melatoninergic inhibitors for acetylserotonin-O-methyltransferase using different docking routines. Theor Biol Med Model 2013;10:63.

12. Mishra A, Dey S. Molecular docking studies of a cyclic octapeptide-cyclosaplin from sandalwood. Biomolecules 2019;9(11):740.

13. Rao C V, Janakiram NB, Mohammed A. Molecular pathways: mucins and drug delivery in cancer. Clin Cancer Res 2017;23:1373-1378.

14. Aslan M, Shahbazi R, Ulubayram K, Ozpolat B. Targeted therapies for pancreatic cancer and hurdles ahead. Anticancer Res 2018;38:6591-6606.

15. Jung HW, Mahesh R, Lee JG, et al. Pinoresinol from the fruits of Forsythia koreana inhibits inflammatory responses in LPS-activated microglia. Neurosci Lett 2010;480:215-220.

16. Sepporta MV, Mazza T, Morozzi G, Fabiani R. Pinoresinol inhibits proliferation and induces differentiation on human HL60 leukemia cells. Nutr Cancer 2013;65:1208-1218.

17. Cristea S, Sage J. Is the canonical RAF/MEK/ERK signaling pathway a therapeutic target in SCLC? J Thorac Oncol 2016;11:1233-1241.

18. Wang L, Yang $X$, An N, Liu J. Bioinformatics analysis of BUB1 expression and gene regulation network in lung adenocarcinoma. Transl Cancer Res 2020;9:4820-4833.

19. Bonofiglio D, Aquila S, Catalano S, et al. Peroxisome proliferator-activated receptor- $y$ activates p53 gene promoter binding to the nuclear factor-kB sequence in human MCF7 breast cancer cells. Mol Endocrinol 2006;20:3083-92.

20. During A, Debouche C, Raas T, Larondelle Y. Among plant lignans, pinoresinol has the strongest antiinammatory properties in human intestinal Caco-2 cells. J Nutr 2012;142:1798-1805.

21. Tian X, Wang N. Upregulation of ASPM, BUB1B and SPDL1 in tumor tissues predicts poor survival in patients with pancreatic ductal adenocarcinoma. Oncol Lett 2020;19:3307-3315.

22. Ricke RM, Van Deursen JM. Aurora B hyperactivation by Bub1 overexpression promotes chromosome missegregation. Cell Cycle 2011;10:3645-3651.

23. Tian T, Sun J, Wang J, et al. Isoliquiritigenin inhibits cell proliferation and migration through the PI3K/AKT signaling pathway in A549 lung cancer cells. Oncol Lett 2018;16:6133-61339.

24. Lee $\mathrm{CH}$, Kim HD, Shin SM, Kim SG. A novel mechanism of PPARy regulation of TGF $\beta$ 1: Implication in cancer biology. PPAR Res 2008;2008: 762398.

25. Nyati S, Schinske-Sebolt K, Pitchiaya S, et al. Cancer: The kinase activity of the Ser/Thr kinase BUB1 promotes TGF- $\beta$ signaling. Sci Signal 2015;8(358):ra1.

26. Zhang Y, Xia M, Jin K, et al. Function of the c-Met receptor tyrosine kinase in carcinogenesis and associated therapeutic opportunities. Mol Cancer 2018;17(1):45.

27. Wang KL, Yu YC, Hsia SM. Perspectives on the role of isoliquiritigenin in cancer. Cancers (Basel) 2021;13:115.

28. Szamborska-Gbur A, Rutkowska E, Dreas A, et al. How to design potent and selective DYRK1B inhibitors? Molecular modeling study. J Mol Model 2019;25(2):41. 